\title{
How Gender-friendly Constructivist Approaches Facilitate the Development of STEM Skills
}

\author{
Ruby Hanson \\ Department of Chemistry Education \\ University of Education, Winneba, Ghana
}

\begin{abstract}
Students tend to perform well in free space learning environments as they are able to put forth ideas that teachers can harness. This study reviewed an integrated STEM constructivist, gender-friendly style that enabled the implementation of students' ideas, transformation of learning environments, instruction, and assessment procedures into meaningful events for lifelong skills among 103 students, 39 of whom were females, in a qualitative case study design that employed the action research approach with interpretive undertones. It used the theoretical framework of phenomenography. The main question that guided the study was to find out about the outcome of integrated STEM constructivist, gender-friendly strategies in lessons and how it affected STEM concept formation and cognitive gains. Tools that were used to gather data were realworld concept-based micro projects and microscience activities. Guided conversations were employed to triangulate data. It was found that it was possible to integrate gender constructivist strategies into lessons to enhance participants' STEM skills acquisition and conceptual gains, especially among females.
\end{abstract}

\section{Introduction}

Research indicates that lack of hands-on projects, opportunities to take risks with mistakes, collaborative teaching styles, accurate perceptions about Science, technology, engineering and mathematics (STEM) careers and culturally innate lack of confidence, deter students, especially females, from science, technology, engineering and mathematics [1]. Current reforms in science curricula require that science is taught in practical ways, taking into consideration learners' environmental and cultural contexts and the seeming increase in female enrolment. There is also a demand in integration between science, technology, engineering and mathematics [2,3]. STEM has no universal definition, yet experts agree that its knowledge could be applied to solve problems and sustain the world [4]. This is because STEM lessons begin with real world problem issues that offer opportunities to learners to experience real-world contexts in interdisciplinary ways as tomorrow's occupations such as actuaries, civil engineers, statisticians, science teachers, software developers, environmental science technologists, biomedical engineers, to name a few are found in it. STEM increases students' achievements in innovative science and provide a continuous pathway of education that create STEMliterate graduates who can accept the challenges of higher education to meet the needs of future workforce. STEM is based on the idea of educating students in multidisciplinary and applied approaches to create critical thinkers, increase science literacy and generations of innovators. These interpretations highlight integrated STEM as divergent from traditional instruction with respect to both content and pedagogy $[5,6]$.

Figures from literature indicates that only $12 \%$ of women engineers are in the workforce and $26 \%$ of that in computing disciplines. In terms of underrepresented minority, $3 \%$ have bachelors in engineering, $5 \%$ in computer science, $6 \%$ in physical science and $8 \%$ in science education [1]. U.S Bureau of Labour Statistics reported that STEM related workforce grew by $10.5 \%$, between May 2009 and May 2015 compared with 5.2\% net growth in nonSTEM related workforce implying high demand for STEM related occupations [3]. In addition, it is predicted that $47 \%$ of today's jobs will require technological development [7] so workforce must be prepared to use their expertise to support government effort and develop scientific literate citizen.

\section{Preliminary Studies}

In order to attempt a reversal of the current situation, it was necessary to integrate STEM in lessons in selected deprived Ghanaian high schools, with rich culture and communal support. Some of the steps taken were to deliberately co-create solutions with all students, especially girls, to positively impact their communities in their everyday activities. In this wise, lessons that subtly embedded the importance of science and mathematics that had the capacity to solve problems were designed with diverse girls and communities in mind, though both genders were assigned same tasks in class.

Real-world problems were created for solution in teams. The female-centric ecosystems were strengthened with personal success stories from 
female teachers and invited role models. Stories were told with enthusiasm and passion to stimulate a liking for STEM-based careers. Then, context-based projects which required engagement with real-life situations in students' communities were assigned to them to involve community members. Some were how to wire a house for energy efficiency, prevent flooding of a bridge during rainfall, design and dye fabric, make earthenware (pottery) and prepare gari, taking note of the STEM procedures and connections. In most cases, students gathered information independently and tried to find connections between disciplines, after which findings were presented for whole class discussions. Scientific inquiry, engineering design processes, appropriate mathematical language, and other skills were expected to be applied where necessary to solve the real-world tasks. Effective instruction in STEM concepts relies on effective instructional methods that commands student attention, learning and retention [8].The teaching approaches that were employed by teachers were all constructivist-based so that students could develop their own authentic knowledge. Thus, inquiry, problem-based and project-based learning strategies were employed throughout the STEMintegration process though about six approaches were available to them. Students were made to reflect after self-assessment sessions in order to unconsciously imbibe desired habits. This paper therefore focused on the evaluation of the implemented STEM programme in terms of the set objectives.

Prior to the current study, STEM had been integrated into lessons by using the Analysis, Design, Development Implementation, and Evaluation (ADDIE) model applied by some researchers [9, 10]. The situation that pertained in ten high schools were analysed for needs, students' content knowledge about STEM and its disciplines, various delivery modes, and possibilities of integrated learning environments, especially in a blended mode. This led to a design phase where objectives and tools for facilitation of the STEM was selected and translated into concrete products for delivery of concepts and skills in the development phase. The integrated STEM programme was purposely to prepare workforce supply demands, improve innovation and ensure social equity with emphasis on girls as they are highly underrepresented [2].

The theoretical framework for integrating STEM was a phenomenonical approach to teaching two or more STEM domains, bound by STEM practices within an authentic context for the purpose of connecting subjects to enhance student learning [11] as they must be equipped with $21^{\text {st }}$ century skills. The STEM integration framework included six tenets which were motivating and engaging content, inclusion of mathematics and science content, student-centred pedagogies, engineering designs, teamwork and communication, and developmental learning [12] in a constructive manner. The tenets of constructivism are also embedded in STEM. Constructivism is a learning theory that gives prominence to active learner participation. Its tenets seek to situate learning and problem-solving in reallife contexts, use authentic tasks, and nurture reflectivity. The method it assumes is the presumption that learners learn best by interacting with the environment and that knowledge, as a function of cognition, is adaptive and organises one's experiential world [13]

Gender, historically referred to only women, and differentiated between masculinity and femininity but is now a spectrum and not a binary [14]. Gender friendliness of curricula changes and modes of assessment affect the pursuit of STEM programmes as it improves learning with visible, tangible technological achievements Gender-inclusive science education leads to different ways of learning rooted in societal roles, which gives the purpose of education a new scope on how students learn and role of teachers [1].

The framework for the current study was phenomenography as it was based on the different ways in which people experience, interpret, perceive and conceptualise some phenomenon. As such, sample and experience were considered as a whole. There was no wrong or right in the integrated STEM investigated or what was real but how participants conceptualised the STEM so that their statements were regarded as truthful by the researcher $[15,16]$. The main objective was to find out the impact of the gender-friendly constructivist STEM approaches that encourage females to show interest in STEM and contribute to findings on STEM that meet national needs.

\section{Methodology}

A qualitative approach using purposeful sampling was used to answer the research question. A purposeful homogenous sample of 103 students participated. These participants should had experienced the integrated STEM for a term as described earlier and could provide information-rich data. Observation checklist, guided conversation, practical activities with Dext science and microscience kits were employed for data collection. Three integrated-STEM lessons that were girl centric biased were observed. From the checklist, students were expected to be seen to developing proposals, drawing designs for assigned real-world problems in independent and collaborative ways, applying mathematical skills, assessing short and long-term environmental and social impacts in scientific ways. The guided conversation which involved 10\% [17] each of boys (6) and girls (4) probed to find out the usefulness and impact of the integrated STEM programme was audio recorded. Transcripts were read severally and coded. The codes were revisited, revised, and elaborated, after which semantic themes 
were developed as semantic themes attempt to identify obvious meanings of interviews by comparing data with that of past to draw inferences.

\section{Results and Discussion}

This study employed a phenomenological, interpretive case study design to develop an understanding of the nature of integrated STEM after which the programme was evaluated with one school to find their experiences with the programme. Dare, Ellis and Roehrig [18] followed a similar protocol. The phenomenological lens used in this study research enabled the researcher to understand what practicing integrated STEM was like for students by focusing on their broad description of experiences. The theoretical framework also made assumptions about the form of integrated STEM, as the objective was to understand its very nature the very nature.

From the three observed integrated STEM lessons, it was identified that peer-led, problem- and projectbased learning were effective, interesting, and engaging and could be said to be gender-friendly pedagogies as they enhanced students' acquisition of STEM skills. Teachers unobtrusively acted as facilitators to give adequate scaffolding to students as they completed their proposed tasks. Yet, students' own knowledge that they brought to school was tapped to encourage and engage them in tasks. Their daily realities were useful starters for helping them to observe and understand their community as they connected with STEM to make science come alive in a meaningful true-to-life manner [19, 20]. The realtime experiences allowed for prediction, observation, hypothesising, conceptualisation, communication, manipulation, computation, elucidation of patterns, reflection, assertiveness, and fluency in science language [8]. Classroom activities such as story boards, concept cartoons, diagrammatic worksheets, word sheets, tiered assessments, coupled with projects and microscience activities supported the embedded constructivist approach in STEM learning. Outcomes of their STEM projects gave them the propensity to change societal and natural orientations.

Classroom activities/experiments in lessons supported the learning process. Attributes such as carefulness, honesty, patience, analytical, predictive, time management, critical thinking, deductive and reflective skills necessary for the development of STEM disciplines were observed to be more obvious among females as they carried out microscience activities. The females, especially were observed to be prepared to learn from risks, which traditional learning spaces mitigate. Observations showed that the females were adept at handling the microscience kits and completed tasks faster with them.

Outcomes from interview sessions showed that female students had positive experiences within the flexible gender constructivist environment. Thus, gender-friendly environments show possibilities for change towards the promotion and advancement of STEM among females with authentic topics, links to everyday student-life, increased hands-on activities, real environmental STEM projects and direct involvement of scientists and other community members. An unedited comment from each of the interviewees is presented.

Jude: The many hands-on activities in different ways- math, chemistry, physics, environmental science- has made me wise...smarter in science, because we virtually do everything ourselves with Ms. Attu supervising until we succeed so you can remember everything that you have done yourself very well.

Abena: I was motivated and excited during STEM projects and saw excitement among my colleagues during science lessons. It was often involving because you do math, you have to remember some science principles and design a solution for a next project but we loved it, especially my girlfriends. The togetherness was fun.

Eric: I loved the 'open air' science where we worked in the community and members saw us as real scientists. Parents think it is prestigious to read science so I loved that my community saw me. It made me work harder and will love to be a great engineer.

Akos: The STEM is like combined science. Here you learn everything in one lesson, even though the lessons are longer. It is better this way because every topic had the biology, chemistry, engineering math, art ..... everything.; even essay or report. It is better, ma'am. Physics alone... I don't know what to do with it. It is dry.

James: I love to build things like planes, trains, some toys for play, but I never knew that I had to do a bit of chemistry...like knowing about the kinds of useful materials and their types....properties and the best ones to use for efficiency. See, with the Ship project, we had revise properties of matter in our group, work on alloys, weigh, measure...put the manufactured toy in water and think of density, then the real field work was great. I really want to be a proper scientist....a good one... build road, bridges, ...now I know.

Tom: Doctor, with STEM it is like science is us, and we are science; I mean us and the environment are one. Science is everywhere. Some projects are difficult but as you move on you see that you apply some drawing to scale, do some measurement or calculation, colour, sometimes even plant something (agric). The projects make you think critically and you are careful too because everything you do must be related intelligibly with another.

Edem: Now we don't have to meet with the Math teacher often because we do enough Math with Ms. Attu. She said the Math covers most of the topics we need to know and I like it in her class because you see that we are doing calculations for proper things like how we measured length and weight of materials to find density of a sheet we needed to build. That was 
very real, not just working and working in Mr. Paul's Math class. Ms. Attu's math was for proper things (a good cause or real-world experience).

Osom: Whenever we did the micro activity and then we went to the pharmaceutical company lab we saw them doing same and their explanations were like what we had found so we could rub shoulders with them. We answered their questions correctly and asked good questions so they asked us to come often. I used some of the knowledge that we gained from them in a chemistry project with ease.

Guided conversations showed that females had positive experiences with MSE.

Mary: I loved the community work most. You can see the science in many things that are parents do at home like the 'akpeteshie' (local alcohol), gari, bread, beads, pottery, are all science. I encouraged some women to make akpeteshie from their fruits like we did in our microscience and they did. I explained the science in it to them and they were excited. I was happy to help as encouraged by Prof. Mrs Appiah when she came to tell us how we can become great scientist like her through such means.

Jane: I loved to use the Dext and MSE kits. They are tiny like play things but they make you get your results pretty fast as you use very little chemical and reach end points faster. Besides, you feel freer working with them because they will not break to hurt you or spill to give you burns. It is better than the big glassware because the drug industry and laboratory at the hospital uses such small equipment. Also, you get time to discuss and understand more. I liked building robots also.

Findings from the conversations suggest that the flexible learning space proved to be an interesting learning environment and impacted on them positively. Students felt that the high percentage of hands-on activities included in their curricula was the reason for success with projects. Many of the students admitted to positive changes in cognitive affective, social, perseverance, self-respect, respect for others, collaborative, and process skills. The creation of a STEM community by inviting role models, sending students out into the community to solve real-life problems, to see people in indigenous industry and discuss the underlying science principles in their work helped to bridge some gender gap in STEM fields. In this study, most of the community projects involved indigenous science, where women were observed making local foods, beads, pottery, blacksmithing (production of alloys) and alcohol. These women were equally excited to engage with the students as they explained the science in their indigenous crafts to them. The women in turn spurred the students on to learn harder so that they could develop better ways of improving their indigenous arts. Students alluded to some benefits that could be gained from communal activities and role models. These real-life meaningful contexts were seen by students as important to higher education and service to the nation. It afforded them the opportunity to improve on their tolerance and collaborative skills through enjoyable activities. The STEM activities signalled a significant shift in the way math and other science disciplines were taught and the way science classrooms functioned.

\section{Conclusion}

In this study, with the use of microscience equipment, other aspects of integrated STEM were uncovered. Students get more time for discussion and confirmation of facts if they perform micro activities. This does not only save students time for discussion and reflection but they tend to have more practice and save the environment as well. Many of the students were observed to display diverse social and affective skills as they performed activities and worked on classroom and community projects. In all of such instances they demonstrated and attested to increased cognitive, process, manipulative and scientific skills. Thus, integrating STEM into curricula could help students into a deeper level of learning with enjoyable, meaningful experiences as the element of freedom allowed them to explore diverse problemsolving routes [1]. The skills obtained could have practical significance for the future. They also demonstrated how knowledge gained from real-world situations could be used to solve problems in school and vice versa. Teachers could therefore use integrated STEM classrooms to provide context to students about how what they were learning could be used for their future careers. The study provides a window into what an integrated STEM education could look like in practice in contemporary science classrooms which could focus more on integration than just sequencing of concepts in a STEM unit [18, 20, 19].

\section{References}

[1] K. Sammet and L. Kekelis, "Changing the game for girls in STEM: Findings oh high impact programs and systembuilding strategies," Techbridgegirls, Oakland, 2016.

[2] C. M. Sias, L. S. Nadelson, S. M. Juth and A. L. Seifert, "The best laid plans: Educational innovation in elementary teacher generated integrated STEM lesson plans," Journal of Educational Research, vol. 110, no. 3, pp. 227-238, 2017.

[3] S. Fayer, A. Lacey and A. Watson, BLS spotlight on statistics: STEM Occupations: Past, present and future, Washington, D.C: US Department of Labour, Bureau of Labour Statistics, 2017.

[4] H. Wang, T. J. Moore, G. H. Roehrig and M. S. Park, "STEM integration: Teacher perceptions and practice," Journal of Pre-College Engineering Education Research, vol. 1, no. 2, pp. 1-13, 2011.

[5] R. W. Bybee, A case for STEM education, Arlington, VA: NSTA Press, 2013. 
[6] J. Vasquez, C. Sneider and M. Corner, STEM lesson essentials, grades 3-8: Integrating science, technology, engineering and mathematics, Portsmouth, NH: Heinemann, 2013.

[7] C. B. Frey and M. A. Osborne, "The future of employment: How susceptible are jobs to computerisation?", Technological Forecasting and Social Change, vol. 114, pp. 254-280, 2017.

[8] R. Hanson, "Chemistry teachers' interpretations of some students' alternative conceptions- A pilot study," African Journal of Chemical Education, pp. 69-96, 2020.

[9] T. T. Lee, A. M. Sahrif and N. Rahim, "Designing Econtent for teaching basic chemistry concepts in higher education: A needs analysis," Journal of Turkish Science Education, vol. 15, no. 4, pp. 65-78, 2018.

[10] L. L. Chen, "A model for effective online instructional design," Literacy Information and Computer Education Journal, vol. 6, no. 2, pp. 2302-2308, 2016.

[11] T. R. Kelly and J. G. Knowles, "A conceptual framework for integrated STEM education," International Journal of STEM Education, vol. 3, no. 11, pp. 2-11, 2016.

[12] T. J. Moore, M. S. Stohlmann, H.-H. Wang, K. M. Tank, A. Glancy and G. H. Roehrig, "Implementation and integration of engineering in K-12 STEM education," in Engineering in precollege settings: Research into practice, West Lafayette, Purdue University Press, 2014, pp. 35-59.

[13] D. A. Kolb, Experiential learning: experience as the source of learning and development, Englewood Cliffs, NJ: Prentice Hall, 1984.

[14] J. Acker, "Inequalities of regimes: Gender, class and race in organisations," Gender and Society, pp. 441-464, 2006.

[15] N. 1. Burrows, M. K. Nowak and S. R. Mooring, "Students' perceptions of a project-based organic chemistry lboratory environment: a phenomenographic approach," Chemistry Education Research and Practice, vol. 18, pp. 811-824, 2017.

[16] M. Orgill and G. Bodner, "What research tells us about using analogies to teach chemistry," Chemistry Education Research and Practice, vol. 5, no. 1, pp. 15-32, 2004.

[17] D. B. Van Dalen, Understanding educational research: An introduction, New York: McGraw-Hill, 1979.

[18] E. A. Dare, J. A. Ellis and G. H. Roehrig, "Understanding science teachers' implementations of integrated STEM curricular units through phenomenological multiple case study," International Journal of STEM Education, pp. 1-19, 2018.

[19] K. L. Smith, J. Rayfield and B. R. McKim, "Effective practices in STEM integration: Describing teachers' perceptions and instructional method use," Journal of Agricultural Education, vol. 56, no. 4, pp. 182-201, 2015.

[20] M. B. Butler and C. Nesbit, "Using science notebooks to improve writing skills and conceptual understanding," Science Activities, vol. 44, pp. 137-145, 2008.

[21] N. F. Ramli, O. Talib, U. K. Manaf and S. Hassan, Instructional approaches and challenges of STEM instructional implementation: A systematic review, Putra: Universiti Putra, Malaysia, 2017. 